\title{
EL VIACRUCIS DE IAAS REVISTAS MEDICAS
}

Cuando la Directiva de una Sociedad Cientifica nos concede el honor de dirigir su Revista, sentimos un positivo orgullo y lo tomamos como un nuevo título, como una distinción y con entusiasmo buscamos la manera de sostener e impulsar lo que otros Directores hicieron por ella.

El material científico lo produce la Sociedad, gracias a sus reuniones periódicas fijas y a la calidad de los trabajos que cada vez son más densos y revelan el fruto de una dedicación por parte de la Cátedra en Hospitales y de los demás socios en diversas Instituciones. En el caso concreto de esta Revista, por servir a una especialidad, es más difícil completar el material para ediciones frecuentes.

Pero el verdadero escollo se aprecia cuando se prepara la edición.

Como muy claramente lo anota el Dr. Alberto Robledo Clavijo en ANTIOQUIA MEDICA Vol. $17 N^{0} 1,1967$, el precio del papel cambia casi para cada edición y siempre en ascenso. Además, con frecuencia es difícil conseguirlo a cualquier precio. $Y$ así llegamos a la financiación. Cuando no se cuenta con ayuda fija de ninguna entidad, el proceso se hace por demás penoso.

Aqui tenemos que referirnos también a los Laboratorios o Empresas vendedoras de Drogas. Estas se han multiplicado apreciablemente y quizá en su emulación el público salga favorecido por la calidad que debe resultar de una competencia sana. Pero la ayuda que en propaganda se daba antes a las Revistas Científicas, es cada día más esquiva e implica para sus Directores una posición casi de súplica el solicitarla.

Debemos un agradecimiento muy especial a los Laboratorios que superando inconvenientes, han comprendido la necesidad de apoyar las 
publicaciones científicas y aún nos acompañan. Pero la mayoría, se niega a dar la propaganda y en cambio la concentra en un despliegue que podemos llamarlo exagerado.

Sabemos que todos los Laboratorios han tenido problemas con materias primas, importaciones etc., pero los Médicos no dejamos de formular a diario los productos que nos recomiendan y además cuentan con un factor definitivo como es el de que nuestro pueblo colombiano COME DROGAS con más avidez que las comidas y lo hace en gran parte a su elección o guiado por las droguerías y farmacias que le recomiendan su consumo. Cuando hablamos de despliegue exagerado en la propaganda, nos referimos al sistema que usan ahora y que debe ser costoso, consistente en grandes cartones plegados, a varios colores $y$ con los cuales, después de observarlos, francamente no sabemos que hacer, pues ni caben en las papeleras de los consultorios. Otra cosa es el relleno de algodón con que aprisionan en los frascos dos o tres tabletas, para presentarlo por un Agente muy bien entrenado, muy cordial y casi siempre en trance de conferencia.

Hablemos claro y cordialmente: tenemos confianza en el prestigio y la tradición de la mayoría de los Laboratorios; por eso creemos que la propaganda a los Médicos y al público puede ser más discreta y más hien encaminada al apoyo de las publicaciones y de los Congresos Médicos, como antes lo hacían. El servicio que nos prestemos mutuamente, irá en beneficio de todos. 